\title{
Cultura de estímulo à criatividade como instrumentos de processos inovadores
}

Creativity stimulation culture as means for innovative processes

SILVA, Giorgio Gilwan da I Doutorando em Design

Universidade do Vale do Itajaí - UNIVALI I giorgiogilwan@gmail.com

PETRELLI, Marco Aurélio I Doutorando em Design

Universidade Federal de Santa Catarina - UFSC I petrelli@univali.br

FIALHO, Francisco Antônio Pereira I Doutor em Engenharia de Produção

Universidade Federal de Santa Catarina - UFSC I fapfialho@gmail.com

GONÇALVES, Marília Matos I Doutora em Engenharia de Produção

Universidade Federal de Santa Catarina - UFSC I marilinhamt@gmail.com

\begin{abstract}
Resumo
A criatividade é um componente humano e peça fundamental para a competitividade organizacional, sobretudo nestes tempos de mudança constante no ambiente de negócios. Por isso, é necessário que as organizações criem ambientes que estimulem a criatividade de modo às ideias de seus membros possam ser transformadas em inovação. No entanto, existem muitas barreiras para dificultam o processo criativo, como por exemplo, a própria cultura organizacional. Assim, o objetivo deste estudo é verificar as características da cultura de estímulo a criatividades como instrumentos de processos inovadores nas empresas de desenvolvimento de produto. Classifica-se a presente pesquisa, quanto à sua forma em qualitativa, quanto aos objetivos, pesquisa exploratória e descritiva com apresentação de dois casos. Os resultados obtidos indicaram que existe uma relação entre a cultura organizacional de estimulo a criatividade e ao desenvolvimento de produtos, processos ou serviços inovadores. Constatou-se que um dos grandes desafios apresentados às organizações é encontrar meios

\section{Abstract}

Creativity is a human trait and a key factor to organizational competitiveness, especially in the face of constant changes in the business environment. It is necessary for corporations to create environments that encourage creativity so that ideas can be transformed into innovation. However, there are many barriers to the creative process - the organizational culture, for example. This study main objective is to verify the characteristics of creativity stimulation as an innovative process tool for products development in companies. This research is qualitative, exploratory as per the objectives, and descriptive - with two case reports. Results indicate a link between organizational culture of creativity stimulation and the development of innovative products, processes or services. It was found that one of the major challenges faced by corporations is finding ways to eliminate barriers in order to promote the expression of creativity among its coworkers.
\end{abstract} de eliminar barreiras, estimulando a expressão da criatividade entre seus membros.

Palavras chave: Criatividade. Inovação. Cultura organizacional.

Keywords: Creativity. Innovation. Organizational Culture. 


\section{INTRODUC̣ÃO}

No atual cenário e contexto econômico, as empresas necessitam cada vez mais de dinamismo e novas abordagens de gestão para atuar de forma competitiva. A partir dessa premissa, a criatividade se torna crescentemente um diferencial competitivo e essencial para o sucesso das marcas. Porém, o ambiente de trabalho pode influenciar e inspirar as pessoas à criatividade ou inibir a sua expressão. $O$ ambiente empresarial pode influenciar tanto positivamente, quanto negativamente, ao desenvolvimento da criatividade.

Sendo assim, o sucesso no ambiente de trabalho dependerá cada vez mais de ambientes propícios à criatividade, o que está intrinsicamente ligados à motivação dos membros das organizações. Por isso, é importante a qualidade do ambiente de trabalho, onde exista respeito mútuo, confiança efetiva, comunicação facilitada entre todos, espaço adequado ao compartilhamento de conhecimentos e informações, o que favorece a execução do trabalho. $\mathrm{O}$ estímulo à criatividade pode ser fomentado por meio de um processo motivacional em que o trabalhador (ou grupo/setor) que gerar uma nova ideia receba, por exemplo, um percentual financeiro estabelecido pela empresa após comprovação da eficiência do novo processo/procedimento; ou fazendo com que cada inovação seja levada ao conhecimento de toda a empresa, entre seus membros, como forma de criar uma cultura de estímulo à criatividade e inovação. Por isso, muitas empresas incentivam o desenvolvimento da criatividade como forma de capacitar seus gestores e profissionais a conseguirem respaldo em oportunidades, além de ameaças, em processos decisórios. Um profissional criativo consegue encontrar soluções de imediato e possibilita o sucesso da empresa a partir de suas ideias que podem ser inovadoras, principalmente, quando as marcas de sucesso enfrentam problemas concorrenciais e precisam inovar o seu design e posicionamento no mercado. Mas, acontece que muitas vezes, os recursos necessários não estão disponíveis e a melhor alternativa para encontrar uma solução inovadora ou contornar um problema pode ser estabelecida a partir da criatividade. No entanto, podem existir muitas barreiras à criatividade e à inovação no ambiente organizacional, seja pela dificuldade das pessoas em mudar seus procedimentos de trabalho, ou pelo fato da organização não perceber ou não saber aproveitar a capacidade criativa de seus membros, fato que pode estar ligado à cultura organizacional. Por mais que a criatividade se torne uma característica fundamental, muitos profissionais ainda fracassam por não serem capaz de promovê-la. Muitos se defrontam com normas rígidas e padrões de trabalho, deixando de lado a oportunidade em desenvolver algo novo ou promover algo totalmente inovador. Ficam completamente alheios às oportunidades que surgem no mercado. Sendo assim, estando às organizações cientes da influência da experiência pessoal no processo decisório, torna-se necessário o incentivo a criatividade e de uma visão mais holística e menos sistêmica do negócio por parte dos profissionais, possibilitando às organizações, a possibilidade de uma gestão menos racional e mais criativa. Diante destas considerações, o objetivo desse artigo é verificar as características da cultura 
de estímulo a criatividades como instrumentos de processos inovadores nas empresas de desenvolvimento de produto. Busca-se descrever a importância da criatividade no mundo empresarial e as características de ambientes motivadores que valorizem o conhecimento tácito de seus membros.

A pesquisa se justifica por se considerar que a criatividade floresce mais quando o trabalhador realiza seu trabalho mobilizado mais pelo prazer e satisfação do que pela obrigação e dever. Considerando-se que uma preparação sólida não seja uma garantia para a criatividade, é certo que quanto maior a bagagem de conhecimento e experiência, maiores são as chances de se produzirem ideias que sejam inovadoras e de valor para os negócios. Como a origem da inovação reside nas ideias criativas das pessoas, a criatividade tem recebido uma atenção crescente. Ela tem sido apontada como uma habilidade humana crítica, que deve ser canalizada e fortalecida a favor do sucesso da organização. Classifica-se a presente pesquisa, quanto à sua forma em qualitativa, quanto aos objetivos, pesquisa exploratória e descritiva com apresentação de dois casos. Esta apresentação que estimule e favoreça a criatividades de seus profissionais. Quanto aos procedimentos técnicos este estudo contempla uma revisão teórica conceitual sobre a criatividade no processo de inovação e as características de um ambiente organizacional favorável à criatividade e pesquisa de campo. Acredita-se que o estimulo ao desenvolvimento da criatividade podem representar um diferencial competitivo da empresa frente ao mercado.

\section{CRIATIVIDADE E INOVAC̣ÃO NO AMBIENTE ORGANIZACIONAL}

Diante do atual contexto do mercado competitivo, para que as organizações possam permanecer no mercado e conquistar novos consumidores, precisam produzir de modo eficiente, oferecendo qualidade, produtos diferenciados que sejam novidades, ou aperfeiçoar as características de produtos que já estão no mercado, desenvolvendo ou implantando novas ideias ou novos processos, novas tecnologias, isto é, ter componentes novos no sentido de inovar.

Neste ambiente são as pessoas que desenvolvem estas novas ideias, pois a criatividade é uma habilidade humana. Este fato condiciona o processo criativo, uma vez que grande parte da responsabilidade de gerar ideias recai sobre as pessoas.

No âmbito empresarial, é o trabalhador que assume esta tarefa. A sua capacidade para desenvolver ideias, primeiro individualmente e posteriormente em equipe ou no departamento em que trabalha, será determinante para a definição de um projeto inovador que aumente a rentabilidade da empresa. 
Mas, para que isto realmente aconteça, primeiramente é necessário criar ambientes que estimulem a criatividade de seus membros, de modo estes possam ter acesso a novas informações e conhecimentos, compartilhar com todas as equipes de trabalho, trocar ideias e transformá-las em processos ou produtos inovadores.

Segundo Bedani (2012), a inovação passou a ser uma alternativa para promover modificações na organização, seja com o objetivo de responder às mudanças nos ambientes internos ou externos, ou ainda, como uma ação antecipada aos concorrentes, e com o intuito de influenciar o ambiente. Para tanto, apresenta-se conceitos de criatividade e inovação, pois ambas podem participar do processo que resulta na inserção, direta ou indiretamente, de um novo produto ou serviço no mercado. Embora a criatividade, por si só, não seja uma inovação, dela participa de maneira indissociável.

\subsection{Conceitos de Criatividade e Inovação}

Do ponto de vista etimológico, segundo Pereira, Mussi e Kanbeen (1999), o conceito de criatividade está relacionado com o termo criar, do latim creare, que significa dar existência, sair do nada, estabelecer relações até então não estabelecidas pelo universo do indivíduo, visando determinados fins. Em relação ao termo criar, Parolin, Vasconcellos e Bordignon (2006), destacam que ele é basicamente formar, ou seja, poder dar uma forma a algo novo.

Caulkins (2001) entende criatividade como imaginação, insight, invenção, inovação, intuição, iluminação e originalidade. Fonseca (2001 apud SILVA, 2016), também está de acordo com esta ideia, afirmando que ser criativo é ver as coisas do mesmo modo que todo mundo vê, mas ser capaz de pensar de forma diferente sobre elas.

Caulkins (2001) defende que a criatividade nas questões empresariais está relacionada a novas formas de solução de problemas, envolvendo a combinação de ideias de diferentes áreas de conhecimento, com probabilidade de saltos de intuição. Para o autor, a criatividade está relacionada à agregação de valor às ideias, à invenção de produtos, à inovação, etc. O autor afirma que a adequação destas ideias aos objetivos propostos é que diferencia a criatividade da divagação - tão temida no meio empresarial quando se fala em intuição e imaginação.

O conceito de criatividade em si é distinto da ideia de capacidade de inovação. O comportamento criativo é suficiente para gerar novas ideias, enquanto o comportamento inovador inclui, além da novidade da ideia, a sua implementação por meio de ações concretas (YUAN; WOODMAN, 2010). Nesse sentido, a associação entre criatividade e inovação ganhou uma relação estreita a partir da necessidade das empresas participarem no mercado global competitivo, que exige produtos e serviços com algum diferencial que estimule a compra. 
Bedani (2012), por sua vez, apresenta o termo criatividade organizacional como sendo um processo originário das características de personalidade, conhecimento, habilidades e motivação dos membros da organização. Percebese, portanto, que o autor também associa a criatividade do ambiente de trabalho a algo relacionado e proveniente do ser humano.

Mas, ainda que se possa atribuir uma razoável parcela da criatividade a uma característica individual, ela também é fruto de uma coletividade (FLORIDA, 2011; WILSON, 2010), ou seja, o compartilhamento é uma ação importante que possibilita exercer a criatividade em uma ampla gama de processos, atividades, produtos e performances. Daskalaki (2010) defende que o processo criativo não se limita a um projeto específico, mas a um contínuo de relações anteriores e futuras derivadas de um processo cultural com suas condições simbólicas e ancoradas em valores, o que a autora denomina comunidade de trabalho criativo que vai considerar o processo criativo uma ação simultânea entre humanos e não-humanos, ou seja, pessoas, ambientes, objetos e artefatos.

Costa (2000) apresenta quatro grandes dimensões da criatividade, figura 1.

Figura 1 - Dimensões da Criatividade

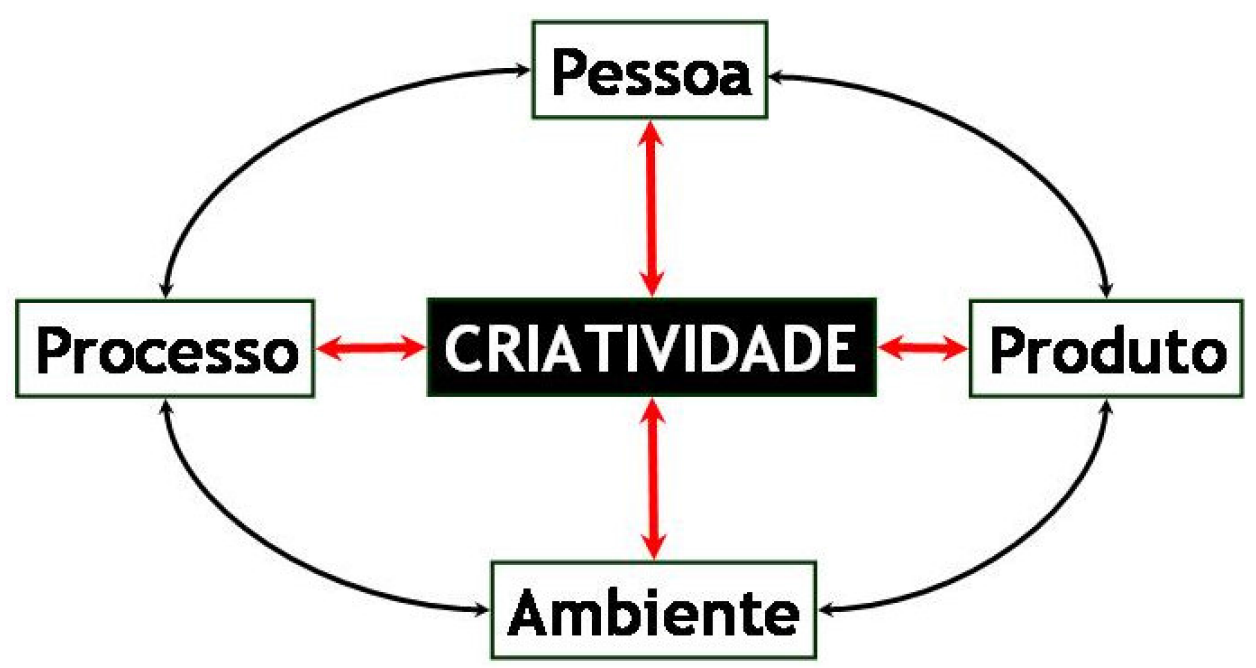

Fonte: Costa (2000, p. 26).

a) Pessoa - um indivíduo criativo que regularmente soluciona problemas, cria produtos ou define novas questões num determinado domínio. O autor acrescenta: fluência, originalidade, elaboração, curiosidade, complexidade, capacidade de assumir riscos, imaginação e abertura. Segundo Colossi (2004), todas as pessoas podem ser criativas, considerando a criatividade como um recurso de todas as pessoas. $O$ ato criador se expressa de diversas formas e em diversos momentos, e vão desde as pequenas originalidades, presentes no cotidiano de cada um, até às criações mais sofisticadas. 
b) Processo criativo - é a forma, ou o modo como a criatividade ocorre. Colossi (2004) também embasa o procedimento de dividir as etapas do processo criativo em: preparação (coleta de informações sobre o problema que deve ser solucionado), incubação (o problema é esquecido para que a intuição possa agir), iluminação (é quando ocorre a solução do problema ou o surgimento da ideia), e comunicação/verificação (é quando as ideias criadas são submetidas à crítica e análise de sua adequação ao contexto que envolve e a sua eficiência na solução do problema ou para atingir os objetivos traçados).

c) O ambiente - é o contexto, o lugar, a situação em que a atividade ocorre. A criatividade não ocorre ao acaso, mas é influenciada por fatores ambientais, ou seja, os momentos de criação podem ser considerados resultantes de circunstâncias sociais. Sendo assim, o clima-ambiente influencia diretamente no nível de criatividade. Logo, é necessário descobrir quais elementos desse clima-ambiente estimulam ou bloqueiam o aparecimento e o desenvolvimento da criatividade.

d) O produto - os produtos inovadores são avaliados a partir de três diferentes aspectos: novidade: analisa o nível de originalidade de um produto/ serviço; resolução: examina o modo como o produto soluciona o problema ou situação para que foi criado; elaboração e síntese: compreende-se as características do produto que estão para além dos requisitos básicos da resolução do problema, com aspectos como a apresentação, a elegância, a atratividade etc.

É importante entender como a criatividade se insere nas organizações, para assim compreender como ela interfere no contexto econômico. A criatividade é resgatada no processo de trabalho, como um traço característico do empreendedor. $\mathrm{O}$ empreendedor normalmente é uma pessoa ativa, arrojada e disposta a por ideias em prática. Para Loch, Amorim e Schmidt (2003) empreendedor é quem faz acontecer o fluxo criatividade-inovação-negócio. Em seus estudos, identificou no empreendedor uma busca pela criatividade e por sua forma de expressão. $\mathrm{O}$ autor acredita que em decorrência do atual mundo do trabalho, o empreendedorismo emerge como forma de absorver a lacuna deixada com a diminuição das ofertas de emprego, e cria novas oportunidades de inserção no mundo do trabalho.

Diante disso, a criatividade manifesta-se nas organizações, nas pessoas que ali trabalham, nos processos internos e é influenciada pela cultura organizacional dessas empresas.

\subsection{Influência da Cultura Organizacional na Criatividade}

Para Schein (2013), cultura organizacional é definida pelo conjunto estruturado de pressupostos básicos que um determinado grupo descobriu ou desenvolveu ao aprender a lidar com os problemas de adaptação ao ambiente 
externo e de integração interna. Ao serem validados na prática diária, estes pressupostos, são ensinados aos membros da organização como a forma correta de perceber, pensar, sentir e se comportar.

Mas, considerando-se que o uso da criatividade nas organizações é imprescindível na busca da diversificação dos produtos e na antecipação das demandas de mercado, é a cultura organizacional que precisa mudar e garantir a execução de ações nas distintas dimensões da criatividade, apresentadas acima.

Isto significa que as características do ambiente organizacional, de seus membros, bem como os fatores estruturais do grupo, tais como, tempo de trabalho em conjunto, recursos disponíveis e a qualidade das interações são exemplos de ações que podem facilitar o processo criativo. O fato é que, a criatividade é favorecida quando o ambiente de trabalho permite o compartilhamento de conhecimento e de informações, os debates das ideias e a participação de todas as equipes dos setores da empresa.

Alencar (1995, p. 6) reconhece que "um clima favorável à criatividade, aliado à prática intencional do processo de resolução criativa de problemas, facilita a mudança e a introdução bem-sucedida da inovação no contexto organizacional." Assim, as culturas organizacionais apoiadoras da criatividade podem encorajar a implementação de inovações, novas maneiras para resolução de problemas e favorecer a inovação. Mas, a tradição e a cultura organizacional podem impedir a criatividade, com destaca-se na sequencia.

\subsection{Barreiras à Criatividade}

Introduzir mudanças no ambiente de trabalho nem sempre é algo simples, como se poderia supor em um primeiro momento. Isto de deve ao fato de que a resistência à mudança é algo muito frequente no comportamento humano. São muitas as barreiras que dificultam a implantação de novas tecnologias e procedimentos de trabalho, pelo medo do desconhecido e de correr riscos.

A tradição e a cultura organizacional são fatores que também impedem a implantação de ações e processos criativos. Desse modo, na visão de Bedani (2012, p. 169), organizações arraigadas às suas tradições, que primam pela manutenção dos seus costumes, serão mais resistentes em aceitar e implementar uma novidade, visto que isso resulta em mudanças nos padrões estabelecidos, representando uma ameaça de ruptura dos modelos tradicionalmente adotados.

As questões mais apontadas pelos autores referenciados neste estudo, como barreiras a criatividade são: a estrutura organizacional; falta de incentivo a capacitação; não propiciar o compartilhamento de conhecimentos e 
informações entre os funcionários e não usar as sugestões, infraestrutura física insuficiente as necessidades, tarefas repetitivas e monótonas, falta de liberdade e autonomia, volume elevado de serviços, e exigências extremas, ambiente que pune o erro dos funcionários, que não estimula a cooperação entre as áreas e que privilegia o controle em detrimento da liberdade dos seus trabalhadores.

Portanto, é um grande desafio para às organizações encontrar meios de eliminar barreiras, estimulando a expressão da criatividade entre seus membros. Alguns autores, têm indicado os conceitos do design thinking que representa uma abordagem contemporânea com propósito de aperfeiçoar a confiança na criatividade do indivíduo e no processo de solução criativa de problemas em que sua principal premissa é que ao entender os métodos e processos os profissionais podem gerar soluções.

\subsection{Ações que Estimulam a Criatividade}

Como pode ser constado acima, na fala dos autores referenciados, a criatividade está baseada na busca pelo novo, pelo surpreendente, pela inovação, entende-se que nesse mesmo sentido, a cultura e as relações organizacionais devem ser revistas, ou seja, mudar a forma de pensar e agir na gestão das pessoas e dos recursos disponíveis. Não mais para manter equipes isoladas, cada uma com sua tarefa específica, pelo contrário todos os integrantes precisam ter uma visão integrada dos projetos, processos e princípios de organização, oferecendo assim, maiores condições de desenvolvimento da criatividade.

Destacam-se alguns fatores colocados por Alencar (1995, p. 8) como sendo favoráveis à criatividade e inovação em uma empresa:

a) Autonomia: grau em que se dá aos funcionários liberdade para inovar;

b) Sistema de premiação dependente do desempenho: considera-se que há maior probabilidade de surgirem novas ideias quando os funcionários percebem que o sistema de premiação é justo e apropriado, e se baseia na competência e desempenho;

c) Apoio à criatividade: percepção, por parte dos funcionários, de que a organização está aberta a novas ideias;

d) Aceitação das diferenças e interesse pela diversidade entre os membros: propostas inovadoras ocorrem quando há espaço para a divergência de pontos de vista e propostas;

e) Envolvimento pessoal: um indivíduo motivado, com alto grau de envolvimento, apresentará certamente alto nível de dedicação ao trabalho;

f) Apoio da direção: um clima criativo só ocorrerá caso haja apoio dos escalões superiores da organização.

Por sua vez, Volpato e Cimbalista (2002) defende que o sucesso no ambiente de trabalho dependerá cada vez mais de ambientes propícios à criatividade e inovação, e que esses fenômenos estão intrinsicamente ligados 
à motivação dos funcionários. Isto significa que a gestão empresarial é que tem que motivar o trabalhador, dando-Ihe credibilidade em sua participação no processo. Este tem que se sentir parte integrante do processo, valorizado, podendo assim, vivenciar e compartilhar seus conhecimentos com os demais membros da organização e por sua vez ampliar seus conhecimentos. Para alcançar altos níveis de produtividade o ambiente de trabalho tem que ser de respeito mútuo e confiança efetiva.

Contudo, a autora adverte quanto às incoerências entre o prescrito $\mathrm{e}$ o vivido - entre o discurso e a prática - que demandam uma revisão profunda dos objetivos, dos reais valores e das culturas que realmente deveriam ser implementadas na organização. No discurso, os gestores de Recursos Humanos classificam as pessoas como recursos estratégicos na organização, mas na prática elas continuam a ser consideradas como custo.

Para Volpato e Cimbalista (2002), a gestão da criatividade orientada à inovação deve ter a preocupação de ouvir seus funcionários e valorizar seu conhecimento tácito: ao serem reconhecidas pelos seus pares e se sentirem realizados, tanto no aspecto econômico como no pessoal, cria-se um ciclo virtuoso onde o trabalhador motivado, irá criar mais, dali, irá inovar mais e tudo reiniciará, por ele ficar cada vez mais motivado.

Porém, o indivíduo criativo muitas vezes não possui a capacidade de fomentar esse ambiente sozinho, em virtude, por exemplo, dos sistemas regulatórios ou dos valores culturais. Nesse sentido, como o novo requer o gerenciamento de processos complexos, o olhar individual pode não ser suficiente para consagrar um insight individual. O compartilhamento de ideias por grupos interdisciplinares potencializa a eficácia do processo criativo. Nesse sentido, uma atitude gerencial criativa poderia fomentar esses grupos, bem como agir para garantir uma eficiência em seus processos e uma eficácia de seus resultados.

Portanto, é importante fomentar uma cultura criativa com enfoque mais abrangente, afetando todos os processos internos e departamentos da empresa. Neste sentido, Alencar (1998) explica que o estabelecimento de uma cultura criativa na empresa está mais relacionado com a implementação de ações e procedimentos que visem:

a) Flexibilizar e superar enfoques de gestão, estruturas e procedimentos rígidos;

b) Aumentar a pro atividade, convertendo o trabalhador em protagonista da mudança;

c) Selecionar trabalhadores com perfis que contribuam com experiência e conhecimentos para ganhar diversidade na análise e no quotidiano da empresa; 
d) Formação contínua de trabalhadores quer em áreas relacionadas com a atividade da empresa, quer em áreas alheias à mesma, que possam servir para a identificação de novos produtos, serviços, etc.

Constatou-se durante esta pesquisa teórica, que os estudos de Amabile e Gryskiewicz (1989) e Amabile (1996), desenvolvidos por meio de pesquisas sobre ambientes organizacionais e seus efeitos na criatividade pessoal, são os que mais vêm influenciando as pesquisas sobre criatividade em nível mundial. Os autores citados analisaram os aspectos socioambientais relacionados à influência dos fatores do ambiente de trabalho sobre a motivação intrínseca do indivíduo, para um modelo de inovação.

Estes autores abordam o estímulo à criatividade para a inovação na perspectiva sociointeracionista e sugerem as seguintes alternativas de estimulação da criatividade:

a) encorajar a autonomia do indivíduo, evitando controle excessivo e respeitando a individualidade de cada um;

b) cultivar a autonomia e independência enfatizando valores ao invés de regras;

c) ressaltar as realizações ao invés de notas ou prêmios;

d) enfatizar o prazer no ato de aprender;

e) evitar situações de competição;

f) expor os indivíduos a experiências que possam estimular sua criatividade;

g) encorajar comportamentos de questionamento e curiosidade;

h) usar feedback informativo;

i) dar aos indivíduos opções de escolha; e

j) apresentar pessoas criativas como modelos.

Estas abordagens apresentadas se complementam, mas é importante destacar, que a aplicação destes fatores favoráveis à criatividade e inovação, dependem da gestão empresarial, que também tem que ser empreendedora e inovadora. As empresas devem buscar sempre a inovação como solução para se diferenciar no mercado, seja desenvolvendo um produto inédito ou criando uma forma de fazer mais e melhor do que os concorrentes. Para atingir estes objetivos, os fatores favoráveis à criatividade e inovação não podem ficar no discurso, mas ocorrer na prática, estando alinhado com a gestão empresarial estratégica e a cultura da empresa, para que a inovação ocorra. O ambiente organizacional que ofereça recursos, reconhecimento e oportunidades, aumenta a probabilidade de ocorrência de contribuições criativas. Apresentase na sequencia pequenos casos com focos específicos, que exemplificam e fortalecem as reflexões teóricas contextualizadas. Para preservar a identidade da empresa, está será identificada pela sua área de atuação. 


\section{APRESENTAC̣ÃO DE CASOS}

Como já apresentado na introdução esta pesquisa é considerada um estudo exploratório, descritivo, de natureza qualitativa, e com apresentação de dois casos. O procedimento de coleta de dados foi a documental, que teve por intuito o levantamento de informação sobre os casos. Tal busca de dados ocorreu em sites das empresas e matérias imprensas, que serviram de apoio à coleta dos dados primários, pois agindo assim, os pesquisadores se abasteceram previamente de informações a respeito do caso estudado, antes do contato feito por telefone e do envio das perguntas via e-mail.

\subsection{Escritório de Design}

Este escritório trabalha com a categoria Design Produto. Possui um ambiente de trabalho do modelo do escritório aberto, ou seja, não existem barreiras físicas entre os profissionais ao executarem suas atividades. Estas são executadas em conjunto, em um amplo salão, visível a qualquer pessoa que entre na empresa. Os profissionais circulam e se comunicam livremente por suas instalações. No horário de intervalo para o lanche e o almoço, é permitida a utilização de uma sala reservada para relaxar. Neste ambiente tem uma televisão, uma mesa de sinuca e vídeo game. Desta forma, a agencia faz uso de uma prática que está relacionada ao estimulo a criatividade inerente ao espaço físico adequado.

A empresa faz uso de práticas de recompensa monetária, premiando os projetos que mais se destacaram no mercado. No final de cada ano, realiza um evento com a participação da gerência e entrega dos prêmios, como a recompensa monetária e viagens, aos seus criadores. Está pratica tem relação com um clima encorajador e recompensador das ideias criativas dos profissionais na empresa. A criatividade é valorizada.

Aagência temumaárea de pesquisa e desenvolvimento queéresponsável pelas inovações da empresa. Nesta área atua uma equipe multidisciplinar para a criação de novos produtos, com design de produto, gráfico, jornalista, arquiteto e designer de moda, todos envolvidos na função de inovação. Estes profissionais compartilham entre si informações, conhecimentos e ideias até chegar ao produto ideal. As inovações são oriundas, principalmente, das necessidades dos consumidores das marcas, para as quais prestam serviços.

\subsection{Empresa de Estamparia}

Esta empresa de estamparia atende empresas têxteis e de confecção. A tecnologia da informação é um recurso que utiliza para disponibilizar informações e conhecimentos atualizados ao setor de criatividade. A internet e intranet são os meios tecnológicos mais eficazes usados por todos os membros da empresa. Estas ferramentas facilitam a captura e o compartilhamento dos 
dados, informações e conhecimentos para o uso de todos. Os sites especializados disponibilizados pela empresa aos seus funcionários são de fácil entendimento e confiáveis. Estão sempre atualizados com importantes informações sobre as cores, as formas, os estilos, as padronagens e o que os consumidores desejam usar, ouvir, comer, divertir-se, etc. Informações de qualidade auxiliam o processo de desenvolvimento de produto, agregando atributos desejáveis a cada um de seus estágios.

É importante destacar, a participação nas feiras e eventos específicos para o setor têxtil e do vestuário. Os funcionários desta empresa, sempre participam dos principais eventos relacionados com a área de atuação, tanto os nacionais quanto os internacionais. O setor de desenvolvimento de produto, em específico, participa de feiras regionais como Texfair (Feira Internacional da Indústria Têxtil), Febratex (Feira Brasileira para a Indústria Têxtil), e nacionais como FIT (Feira Internacional do Setor Infantil) e a edição nacional da Première Vision. Nas viagens de pesquisa aos países da Europa, inclui-se a participação na Première Vision em Paris e até em feiras menores como a Bubble, em Londres.

Todos os anos, a equipe de desenvolvimento de produto participa do Design Pixel Show, evento brasileiro focado em criatividade e inovações tecnológicas. A participação em eventos artísticos facilita o processo criativo aplicado aos produtos de moda. Expressões artísticas proporcionam ampliação do conhecimento tácito, que podem gerar ideias inovadoras voltadas à diferenciação das estampas exclusivas para as coleções.

A empresa de estamparia tem interesse constante em aprimorar a qualificação profissional de seus funcionários. Uma vez a cada ano, são proferidas palestras com importantes nomes do design e da moda nacional. O objetivo é ampliar o conhecimento dos profissionais que trabalham no setor de criação do produto e estimular a criatividade com exemplos de boas práticas. A empresa contrata Workshop com profissionais especializados para aprimorar o trabalho da equipe, na experimentação de novas técnicas de criatividade e de processos de trabalho.

Além disso, os empregados têm acesso a instalações para a prática de desportos e jogos (ténis de mesa, bilhar, voleibol, etc.) e uma oferta completamente gratuita de serviços adicionais, como jardim-de-infância, lavanderia, sala de massagens e restaurantes. O objetivo é dar aos membros da empresa, também do ponto de vista físico, um universo cativante que lhes permita desenvolver o seu talento e capacidade criativa.

\section{CONCLUSÃO}

A criatividade no ambiente organizacional tem sido foco de muitas pesquisas e estudiosos. No entanto, muitas organizações ainda não perceberam ou não conseguem colocar em prática processos que facilitem a criatividade. 
As empresas ainda têm dificuldades em superar as barreiras à criatividade no ambiente organizacional.

Constatou-se que a cultura organizacional foi apontada pelos autores referenciados como influenciadora da criatividade no ambiente de trabalho. Assim, pesquisa de novas informações, conhecimentos e compartilhamento de ideias entre os diferentes tipos de profissionais, que possam tornar-se inovadoras. Isto ocorre com a criação de ideias, e a respectiva utilização sob a forma de inovação aplicada, permite solucionar problemas que atenda o mercado consumidor, de tal modo que a empresa destaque-se no mercado.

Para permanecerem competitivas no atual contexto do mercado global, as empresas devem estimular ambientes que aceitem as diferenças, incentivem a aceitação de riscos e premiem a inovação, além de fomentar a liberdade para criar e a autonomia dos profissionais.

Identificou-se nos casos apresentados, a existência de ações empresariais que mobilizam os profissionais, na busca de procedimentos que aumentem a sua criatividade. Recompensar ideias criativas das equipes de trabalho pode ser considerado uma estratégia de estímulo à criatividade, conforme abordado na teoria. As pessoas mobilizadas podem buscar novas informações e conhecimentos objetivando a geração de novas ideias.

O ambiente que permite a livre circulação de seus profissionais facilita a interação entre todos, bem como a disseminação das ideias e a criação de novos conhecimentos.

A empresa de estamparia por ser uma empresa de médio porte, tem uma cultura organizacional, totalmente estimuladora com ações que capacitam seus profissionais ao processo criativo. Destaca-se neste contexto, o ambiente de trabalho com espaços e atividades que beneficiam os trabalhadores e liberam a criatividade de maneira relaxante. Isto permite momentos de descanso, favoráveis ao pensamento criativo, pois nestes momentos os indivíduos descansam, libertam suas mentes, e diferentes conexões mentais podem ocorrer transformando-se em novas ideias. 


\section{REFERÊNCIAS}

ALENCAR, Eunice Lima Soriano. Desenvolvendo a criatividade nas organizações o desafio da inovação. Revista de Administração de Empresas, São Paulo, v. 35, n. 6, p. 6-11, 1995.

ALENCAR, Eunice Lima Soriano. Promovendo um ambiente favorável à criatividade nas organizações. Revista de Administração de Empresas, São Paulo, v. 38, n. 2, p. 18-25, 1998.

AMABILE, Terasa A. Creativity in context. Boulder, CO: Westview Press, 1996.

AMABILE, Teresa A.; GRYSKIEWICZ, Nur D. The creative environment scales: work environment inventory. Creativity Research Journal, Cambridge, v. 2, p. 231-253, 1989.

BEDANI, Marcelo. O impacto dos valores organizacionais na percepção de estímulos e barreiras à criatividade no ambiente de trabalho. Revista Administração Mackenzie, São Paulo, v. 13, n. 3, p. 150-176, maio/jun. 2012.

CAULKINS, Kyle Wellington. Criatividade nas organizações. 2001. Trabalho de Conclusão de Curso (Programa Especial de Treinamento do Departamento de Engenharia de Produção e Sistemas) - Universidade Federal de Santa Catarina, Florianópolis, 2001.

COLOSSI, Luciano. Características de ambientes organizacionais orientados ao comportamento criativo. 2004. Dissertação (Mestrado em Psicologia) Universidade Federal de Santa Catarina, Florianópolis, 2004.

COSTA, Maria Helena Gil. Porque a criatividade está na moda, ou porque antes de ser professor sou pessoa. Revista Sonhar, Braga, v. 8, n. 1, p. 125-141, set./dez. 2000. 
DASKALAKI, M. Building 'Bonds' and 'Bridges': linking tie evolution and network identity in the creative industries. Organization Studies, Berlin, v. 31, n. 12, p. 1649-1666, 2010.

FLORIDA, R. A ascensão da classe criativa: e seu papel na transformação do trabalho, do lazer, da comunidade e do cotidiano. Porto Alegre: LPM, 2011.

LOCH, Clésar Luiz; AMORIM, Luciana Martins; SCHMIDT, Luciane Lehmkuhl. Criatividade, trabalho e empreendedorismo. In: ENCONTRO NACIONAL DE EMPREENDEDORISMO, 5., 2003, Florianópolis. Anais... Florianópolis: UNICA - Centro de Educação Superior, 2003. v. 1, p. 1-9.

PAROLIN, Sonia Regina Hierro; VASCONCELLOS, Eduardo; BORDIGNON, João Alberto. Barreiras e facilitadores à inovação: o caso Nutrimental S/A. Revista de Economia Mackenzie, São Paulo, v. 4, n. 4, p. 12-34, jan. 2006.

PEREIRA, Breno Augusto D.; MUSSI; Carlos Wolowski; KANBEEN; Alcina. A influência da criatividade para o sucesso estratégico organizacional. In: ENCONTRO ANUAL DA ASSOCIAÇÃO NACIONAL DOS PROGRAMAS DE PÓS-GRADUAÇÃO EM ADMINISTRAÇÃO, 23., 1999, Foz do Iguaçu. Anais... Foz do Iguaçu, 1999. v. 1, p. 1-10.

SCHEIN, E. Corporate culture. In: VOGELSANG, John et al. Handbook for strategic HR: best practices in organizational development from the OD network. New York: American Management Association, 2013. p. 253-256.

SILVA, Giorgio Gilwan da. Cultura de estímulo à criatividade como instrumentos de processos inovadores. Projética, Londrina, v.7, n.1, p. 9-25, Jan/Jun. 2016.

VOLPATO, Maricilia; CIMBALISTA, Silmara. O processo de motivação como incentivo à inovação nas organizações. Revista da FAE, Curitiba, v. 5, n. 3, p. 75-86, 2002. 
SILVA, Giorgio Gilwan da et al.

WILSON, N. Social creativity: re-qualifying the creative economy. International Journal of Cultural Policy, Coventry, v. 16, n. 3, p. 367-381, 2010.

YUAN, Feirong; WOODMAN, Richard W. Innovative behavior in the workplace: the role of performance and image outcome expectations.

Academy of Management Journal, Champaign, v. 53, n. 2, p. 323-342, 2010.

Submissão: 08-2016

Aceite: 07-2017 